\title{
CONFLITOS DE TRANSPARÊNCIA E CONFIDENCIALIDADE NA CERTIFICAÇÃO DE SISTEMAS DE GESTÃO AMBIENTAL
}

\author{
Alexandre de Oliveira e Aguiar \\ Universidade Nove de Julho - São Paulo, SP / Brasil \\ aaguiar@uninove.br \\ Pedro Luiz Côrtes \\ Universidade de São Paulo - São Paulo, SP / Brasil \\ plcortes@usp.br
}

Recebido em 23/01/2012

Aprovado em 16/07/2013

Disponibilizado em 01/04/2014

Avaliado pelo sistema double blind review

Revista Eletrônica de Administração

Editor: Luís Felipe Nascimento

ISSN 1413-2311 (versão on-line)

Editada pela Escola de Administração da Universidade Federal do Rio Grande do Sul.

Periodicidade: Quadrimestral

Sistema requerido: Adobe Acrobat Reader.

\section{RESUMO}

Todo o processo de certificação pela norma ISO 14001 está baseado em princípios de transparência e disponibilidade de informações. Isto é determinado pela norma ISO / IEC 17021 que é a base para a atuação dos organismos certificadores de sistemas de gestão ambiental ISO 14001. A norma ISO / IEC 17021 estabelece princípios de transparência das informações e determina aos organismos certificadores a obrigação de disponibilizar a lista de clientes certificados. No entanto, muitos organismos certificadores se negam a proporcionar esta informação ao público. Não foram localizados estudos anteriores sobre esta questão em bases científicas. Para tratar do assunto, que se considera importante para a confiabilidade do processo de certificação, foi desenvolvido o presente estudo, tendo como objetivo verificar as dificuldades para se obter informações junto aos organismos certificadores, caracterizando o estado de transparência dessas organizações. Foi solicitada a lista de clientes certificados junto aos 20 organismos certificadores que operam no Brasil sob a acreditação do INMETRO (Instituto Brasileiro de Metrologia, normalização e Qualidade Industrial). Além da acreditação do INMETRO, muitos desses organismos também operam sob acreditações estrangeiras. Somente dez deles fornecem a informação requerida pela norma ISO / IEC 17021 e foram obtidas informações de 934 clientes certificados. Os organismos certificadores que não apresentaram as informações especificadas pela norma ISO / IEC 17021 afirmaram que o sigilo é necessário para preservar a confidencialidade da informação dos clientes. Outras razões foram apresentadas: prevenir os ataques de certificadores competidores, as políticas corporativas e também que não é necessário fornecer a informação. Este estudo conclui que as empresas nem sempre cumprem os requisitos de transparência da norma ISO / IEC 17021 e que são requeridas no sistema de acreditação.

Palavras-chave: Sistemas de gestão ambiental; transparência; certificação; acreditação; ISO 14001; ISO / IEC 17021

REAd | Porto Alegre - Edição 77 - N 1 - janeiro/abril 2014 - p. 31-63 
Conflitos de transparência e confidencialidade na certificação de sistemas de gestão ambiental

\title{
TRANSPARENCY AND CONFIDENTIALITY CONFLICTS IN THE ENVIRONMENTAL MANAGEMENT SYSTEMS CERTIFICATION
}

\begin{abstract}
The ISO 14001 certification process is based upon transparency and information availability principles. This is set by international standard ISO / IEC 17021 which is that basis for the accreditation of organizations that provide ISO 14001 environmental management systems certification. Standard ISO / IEC 17021 establishes principles on information transparency and determines that certification bodies have the obligation of making the directory of certified clients available to the public. However, many of the certification bodies refuse to make this information available. This research has been developed in order to address it. Directory of certified clients has been requested to the 20 certification bodies that operate in Brazil under INMETRO's (Brazilian Institute o Metrology, Standardization and Industrial Quality) accreditation, many of these bodies operate under foreign accreditation as well. Only ten certification bodies made available all the information that is required by ISO / IEC 17021 and information on 934 certified clients have been obtained. Certification bodies that did not made the information available as specified in ISO / IEC 17021 stated that secrecy is necessary to preserve client's information confidentiality. Other reasons that have been said: to prevent attacks by competitors, corporate policies and also that it would not be necessary to give the requested information. This study draws to the conclusion that the certification bodies not always comply with transparency requirements of ISO / IEC 17021 and that are required in the accreditation system.
\end{abstract}

Keywords: Environmental management systems; openness; certification; accreditation; ISO 14001; ISO / IEC 17021

\section{CONFLICTOS DE TRANSPARENCIA Y CONFIDENCIALIDAD EN LA CERTIFICACIÓN DE SISTEMAS DE GESTIÓN AMBIENTAL}

\begin{abstract}
RESUMEN
Todo el proceso de certificación por la norma ISO 14001 está basado en principios de transparencia y disponibilidad de informaciones. Esto es determinado por la norma internacional ISO / IEC 17021 que es la base para la actuación de organismos certificadores de sistemas de gestión ambiental ISO 14001. La norma ISO / IEC 17021 establece principios de transparencia de las informaciones y determina a las compañías certificadoras la obligación de que se ponga disponible la lista de los clientes certificados. Sin embargo, muchas de las compañías certificadoras se niegan a proporcionar esta información al público. Para estudiar esta cuestión, que se considera importante para la fiabilidad del proceso de certificación, fue desarrollado el presente estudio. Se solicitó la lista de clientes certificados junto a los 20 organismos de certificación que operan en Brasil bajo la acreditación del INMETRO (Instituto Brasileño de Metrología, Normalización y Calidad Industrial). Además la acreditación del INMETRO, muchas de esas compañías también operan bajo acreditación extranjera. Sólo diez de ellos proporcionan la información requerida por la norma ISO / IEC 17021 y se obtuve información de 934 clientes certificados. Las empresas certificadoras que no presentaran las informaciones especificadas por la norma ISO / IEC 17021 afirmaran que
\end{abstract}

REAd | Porto Alegre - Edição 77 - N 1 - janeiro/abril 2014 - p. 31-63 
el sigilo es necesario para preservar la confidencialidad de la información de los clientes. Otras razones fueron presentadas: prevenir los ataques de empresas certificadoras competidoras, las políticas corporativas y también que no es necesario proporcionar esta información. Este estudio concluye que los organismos certificadores no siempre cumplen con los quesitos de transparencia de la norma ISO / IEC 17021 y que son requeridas en el sistema de acreditación.

Palabras Clave: Sistemas de gestión ambiental; transparencia de informaciones; certificación; acreditación; ISO 14001; ISO / IEC 17021

\section{INTRODUÇÃO}

De acordo com a norma ISO 14001, a certificação de sistemas de gestão ambiental é um dos instrumentos utilizados pelas empresas que desejam implantar sistemas voltados ao cumprimento de requisitos legais relacionados à prevenção da poluição e demais exigências ambientais associadas. A certificação ISO 14001 também é exigida em algumas cadeias de suprimentos como parte da qualificação de fornecedores, estabelecendo critérios que padronizam e facilitam a avaliação de empresas. Como todo sistema de certificação, tem na transparência uma de suas bases importantes.

Desde a sua concepção, em meados da década de 1990, a norma ISO 14001 tem sido objeto de pesquisas diversas. Para evidenciar isso, foi realizado um levantamento na Web of Science, serviço online disponibilizado pela Thomson Reuters que faz a indexação e permite a busca de trabalhos científicos publicados internacionalmente em diferentes áreas do conhecimento. O levantamento na Web of Science buscou artigos científicos sobre a norma ISO 14001, resultando em 406 trabalhos publicados entre 1994 e 2012, conforme disponível na Tabela 1. O aumento do número de trabalhos sobre o tema evidencia um crescimento do interesse sobre a norma ISO 14001. Verificou-se que, embora as abordagens sejam razoavelmente diversificadas, há uma concentração de trabalhos sobre motivação para implantar essa certificação, obstáculos à adoção da ISO 14001 e benefícios obtidos.

A título de exemplo é possível citar Delmas \& Montiel (2008), ao estudar a difusão internacional das normas de sistemas de gestão no setor químico, entre elas a ISO 14001; Campos et al. (2009), que estudaram a rentabilidade de empresas de capital aberto certificadas ISO 14001; Orsato (2002) que analisou situações propícias ao investimento em gestão ambiental; Prakash \& Potoskim (2006), que ponderaram sua influência do comércio internacional; Ávila \& Paiva (2006), que estudaram os processos operacionais envolvidos na implantação dessa norma, Lopez (2011) que fez um balanço da visão de pessoas envolvidas com a implementação de sistemas de gestão ISO 14001, Yin \& Schmeidler (2009), que 
Conflitos de transparência e confidencialidade na certificação de sistemas de gestão ambiental

procuraram entender as razões dos resultados heterogêneos de certificações ISO 14001; Jabbour (2010), em que o autor pesquisa o estágio de gestão ambiental de empresas certificadas ISO 14001; e Cordeiro et al. (2009) que estudaram como empresas chinesas respondem a pressões por melhorias na gestão ambiental.

Tabela 1 - Artigos sobre a norma ISO 14001 indexados na Web of Science

\begin{tabular}{|c|c|c|c|}
\hline Ano & $\begin{array}{l}\text { Artigos } \\
\text { Publicados }\end{array}$ & $\begin{array}{c}\% \\
\text { (em 406) }\end{array}$ & $\begin{array}{l}\text { Gráfico de } \\
\text { Barras Referenciais }\end{array}$ \\
\hline 2012 & 43 & 10.591 & \\
\hline 2011 & 47 & 11.576 & \\
\hline 2010 & 44 & 10.837 & \\
\hline 2009 & 37 & 9.113 & \\
\hline 2008 & 42 & 10.345 & \\
\hline 2007 & 34 & 8.374 & \\
\hline 2006 & 21 & 5.172 & \\
\hline 2005 & 26 & 6.404 & \\
\hline 2004 & 16 & 3.941 & \\
\hline 2003 & 18 & 4.433 & \\
\hline 2002 & 19 & 4.680 & \\
\hline 2001 & 10 & 2.463 & \\
\hline 2000 & 12 & 2.956 & \\
\hline 1999 & 7 & 1.724 & \\
\hline 1998 & 7 & 1.724 & \\
\hline 1997 & 16 & 3.941 & \\
\hline 1996 & 5 & 1.232 & \\
\hline 1995 & 1 & 0.246 & \\
\hline 1994 & 1 & 0.246 & \\
\hline \multicolumn{4}{|c|}{$\begin{array}{l}\text { Sintaxe utilizada na pesquisa: TopiC=("ISO 14001") Refined by: Document Types=(ARTICLE) } \\
\text { Timespan=All Years. Databases=SCI-EXPANDED, SSCI, A\&HCI, CPCI-S, CPCI-SSH. } \\
\text { Lemmatization=On. }\end{array}$} \\
\hline
\end{tabular}

É interessante notar embora a produção internacional qualificada possa ser considerada relevante, nesse período de 19 anos (1994-2012), 60\% dos trabalhos disponíveis foram publicados no período de 2007 a 2012, com um total de 247 artigos. Nesse período, 34 artigos foram publicados em 2007, 42 em 2008, 37 em 2009, 44 em 2010, 47 em 2011 e 43 em 2012, indicando um crescimento do interesse pela ISO 14001.

A concentração de trabalhos sobre motivação, dificuldades e benefícios, geralmente desenvolvidos sob a forma de estudos de caso ou surveys pode ser entendida diante da carência de estatísticas confiáveis sobre as empresas certificadas, tanto no Brasil quanto no exterior. Isso dificulta, por exemplo, o desenvolvimento de estudos comparativos sobre setores industriais mais aderentes à certificação ou o impacto de políticas públicas na adoção da ISO 14001 em determinados setores, ou uma visão mais geral dos resultados atingidos. Mesmo assim, alguns estudos foram operacionalizados com base em bancos de dados de REAd | Porto Alegre - Edição 77 - N 1 - janeiro/abril 2014 - p. 31-63 
organismos acreditadores, tal como fizeram Yin e Schmeidler (2009), que desenvolveram uma pesquisa utilizando o banco de dados da American National Accreditation Board (ANAB). No Brasil, pesquisadores como Ávila e Paiva (2006) utilizaram o banco de dados disponibilizado pelo INMETRO contando com aproximadamente 600 empresas certificadas, num universo estimado pela ISO (2009) e pela revista Meio Ambiente Industrial (A EVOLUÇÃO, 2005) em aproximadamente 2000 empresas, na época. Atualmente, o banco de dados do INMETRO (2011) conta com menos de 300 empresas, representando um universo bem mais restrito em relação ao total de certificados estimados para o Brasil, enquanto a ISO (2010) estimava mais de 2.000 empresas certificadas e Jucon (2010) estimava na mesma data 4.000 empresas. Outros estudos, como de Delmas e Montiel (2008) utilizam os dados quantitativos disponibilizados pelas estatísticas da própria ISO, os quais também têm deficiências, por exemplo, porque nem todos os organismos certificadores respondem ao survey, o que resulta em um universo conhecido de empresas certificadas menor que o real. Em razão da carência de informações o estudo realizado por Fryxell et al. (2004) acaba sendo uma rara exceção.

Se a falta de precisão sobre a quantidade de empresas certificadas acaba prejudicando o desenvolvimento de determinados estudos, parece correto averiguar quais são as causas dessa imprecisão. Foi considerada a possibilidade de verificar, junto aos organismos certificadores, a quantidade de empresas certificadas. Buscando um melhor entendimento sobre esse tema, foi prospectada a produção de artigos científicos sobre os organismos certificadores. A estratégia de pesquisa foi desenvolvida com auxílio da Web of Knowledge e buscou exclusivamente pelo termo 'ISO/IEC 17021', que é a norma que especifica os procedimentos para a acreditação de organismos que oferecem certificação de sistemas de gestão ambiental. Essa pesquisa resultou como único artigo o trabalho de Ruzevicius (2008), que discorre sobre sistemas de qualidade na Lituânia, sem entrar no aspecto específico da acreditação das empresas certificadoras. Buscando ampliar a estratégia de busca, foi utilizado o termo 'ISO 14001' na Web of Knowledge, que indicou a existência de 202 artigos publicados em inglês entre 2007 e 2011. Com a ajuda do software BibExcel (versão 2011-12-22), foram analisados os abstracts desses artigos procurando-se, inicialmente, pelo termo 'ISO/IEC 17021'. Apenas uma ocorrência foi verificada (RUZEVICIUS, 2008), já mencionado.

Em seguida, nos 202 artigos publicados entre 2007 e 2011, buscou-se o termo 'accreditation' (acreditação). Foram encontrados os seguintes trabalhos: Heras-Saizarbitoria, Molina-Azorin \& Dick (2011), que utilizam o termo 'accreditation' como sinônimo de certificação ao 
Conflitos de transparência e confidencialidade na certificação de sistemas de gestão ambiental

discorrerem sobre a relação entre a ISO 14001 e o desempenho financeiro e Kaziliunas (2008), que fala sobre acreditação quando comenta a importância dos auditores de acordo com o International Accreditation Forum (IAF). Como a pesquisa pelos termos mais específicos (ISO/IEC 17021 e accreditation) não apresentaram resultados envolvendo estudos sobre organismos certificadores, foram utilizados termos mais genéricos e que - em tese poderiam ser relacionados ao processo de certificação. A primeira tentativa foi com a palavra 'openness' (como sinônimo de franqueza e sinceridade), sem qualquer ocorrência. Prosseguiu-se a busca pelo termo 'transparency' (como sinônimo de transparência), verificando-se as seguintes ocorrências: Mitchell \& Hill (2009) e Szper \& Prakash (2011), em um contexto de governança e accountability; Delmas \& Blass (2010) e Mijatovic \& Stokic (2010), discorrendo sobre Responsabilidade Social Empresarial. Essas estratégias evidenciam que não há, entre a produção internacional mais relevante sobre ISO 14001, no período de 2007-2011, artigo que discorre sobre os organismos certificadores.

Para as publicações nacionais o cenário não é mais animador. Inicialmente buscou-se no SciELO os termos 'ISO/IEC 17021' e '17021', sem resultados. Prosseguiu-se com o uso do termo '14001', obtendo-se sete artigos. Faroni, Silveira et al. (2010) desenvolveram um estudo para verificar a utilização de instrumentos da Contabilidade Ambiental em empresas certificadas pela ISO 14001. Rohrich \& Cunha (2004) realizaram uma pesquisa com 37 indústrias no Brasil e propuzeram uma taxonomia para sistemas de gestão ambiental. Oliveira \& Serra (2010), também trabalhando com indústrias, análisaram os benefícios e as dificuldades da adoção da ISO 14001. Oliveira \& Pinheiro (2010), tendo como foco a gestão de pessoas, tecem considerações e apresentam sugestões para o corpo diretivo das organizações, comitê de gestão ambiental, treinamento e comunicação, dentre outras. Pombo \& Magrini (2008) buscaram entender a aderencia das empresas brasileiras à ISO 14.001. Avila \& Paiva (2006), por sua vez, analisaram os resultados operacionais decorrentes da adoção da ISO 14001 nas empresas brasileiras. Moretti, Sautter \& Azevedo (2008) analisam os prós e contras da adoção da ISO 14001, buscando fornecer elementos para a tomada de decisão pelos gestores organizacionais.

O levantamento realizado evidencia que, embora a quantidade de artigos internacinais sobre a ISO 14001 tenha crescido, a atuação dos organismos certificadores não foi abordada. Há uma clara concentração de estudos no outro extremo do processo, envolvendo apenas as empresas certificadas. Diante disso, é possível supor que essa carência de estudos não seja decorrente da ausência de interesse pelo tema, mas de uma falta de informações sobre a atuação dos 
organismos certificadores. Isso remete a um questioamento efetuado inicialmente e que indagava sobre a quantidade de empresas certificadas. Será que uma possível relutância dos organismos certificadores em divulgar a quantidade de certificados emitidos, incluindo informações mais específicas sobre as empresas, conforme determina ISO/IEC 17021, não seria a causa das inconsistências sobre a quantidade de empresas certificadas? Em havendo essa relutância, isso não estaria contrariando a norma ISO/IEC 17021 que estabelece princípios de transparência, determinando a obrigatoriedade das empresas certificadoras disponibilizar a lista de clientes certificados pela ISO 14001 ?

Diante disso, surgiu a questão de pesquisa que norteou o desenvolvimento deste trabalho: "No Brasil, como é disponibilizada a informação sobre as empresas certificadas pela norma ISO 14001?" Acredita-se que a resposta a essa questão permitirá atender aos seguintes objetivos de pesquisa: a) verificar quais as dificuldades para se obter as informações sobre clientes certificados ISO 14001 junto aos organismos certificadores; b) caracterizar o estado de transparência dos organismos certificadores quanto ao fornecimento da relação de empresas certificadas.

Para desenvolver este trabalho, foi elaborada uma estratégia de pesquisa que incluiu, inicialmente, a revisão da literatura sobre a certificação ISO 14001 buscando obter um melhor entendimento dos seguintes itens: i) sistemas de gestão ambiental, ii) acreditação dos organismos certificadores e certificação, iii) a importância da confiança e transparência nos processos de certificação. Como base no entendimento propiciado pela revisão da literatura, foi desenvolvida uma pesquisa para levantamento de informações junto a empresas certificadoras. $\mathrm{O}$ estudo empreendido permitiu verificar como é disponibilizada a informação sobre as empresas certificadas pela ISO 14001, aferindo as dificuldades de acesso a essas informações e caracterizando o estado de transparência dos organismos certificadores.

\section{REVISÃO DA LITERATURA}

A certificação ISO 14001 é regida por um conjunto de regras definidas internacionalmente por organismos não governamentais que se estruturam para criar e dar suporte a implantação de certificaçõoes de sistemas de gestão ambiental, sistemas de gestão da qualidade, entre outros. Uma dificuldade inicial para o desenvolvimento de uma pesquisa tenha significância estatística e que envolva empresas certificadas ISO 14001, é definir o tamanho da população (empresas certificadas), bem como suas características descritivas que permitam obter uma 
Conflitos de transparência e confidencialidade na certificação de sistemas de gestão ambiental

estratificação da amostra (por exemplo, setor da economia em que atua, porte, organismo certificador, etc.).

No Brasil não existe um banco de dados completo e unificado que sirva de referência para o desenvolvimento desse tipo de pesquisa, sendo possível verificar inconsistências nas informações disponíveis. Por exemplo, para o ano de 2009, a ISO indicava a existência, no Brasil, de 1327 empresas certificadas (ISO, 2010). Por outro lado, a revista Meio Ambiente celebrava o total de 4.000 certificações no Brasil (Jucon, 2010) e 5.000 certificações em 2011 (FAVERIN, 2011). Para o ano de 2011, o Instituto Nacional de Metrologia, Normalização e Qualidade Industrial (INMETRO), órgão de acreditação de organismos certificadores no Brasil, indica a existência de menos de 300 empresas certificadas sob a ISO 14001 dentro do Sistema Brasileiro de Acreditação e Certificação (INMETRO 2011).

Percebe-se, na Figura 1, que até 2006 os números de certificados divulgados pela ISO e pela Revista Meio Ambiente Industrial eram aproximadamente coincidentes. Até 2005 a editora publicava a lista das empresas certificadas, com nome e Estado em que se localizavam. $\mathrm{O}$ escopo da certificação não era divulgado. Atualmente os números de ambas as fontes apresentam tendências claramente opostas. A fim de tentar localizar a origem das divergências, em etapas preparatórias desse trabalho, foram entrevistadas pessoas da ISO e da Editora Tocalino, que publica a revista, e ambos confirmaram que os organismos certificadores são a fonte primária dos dados utilizados. Considerando-se o tempo que uma empresa leva para obter uma certificação ISO 14001 e o prazo de validade da mesma, contatase que o processo é relativamente demorado a ponto impedir uma variação significativa no número de certificações no curto prazo. Dessas referências, a única que ainda apresenta listas de empresas certificadas é a base de dados do INMETRO, que logo num primeiro momento já aparece como possivelmente incompleta e pouco representativa do universo de empresas com certificado ISO 14001 no Brasil. 


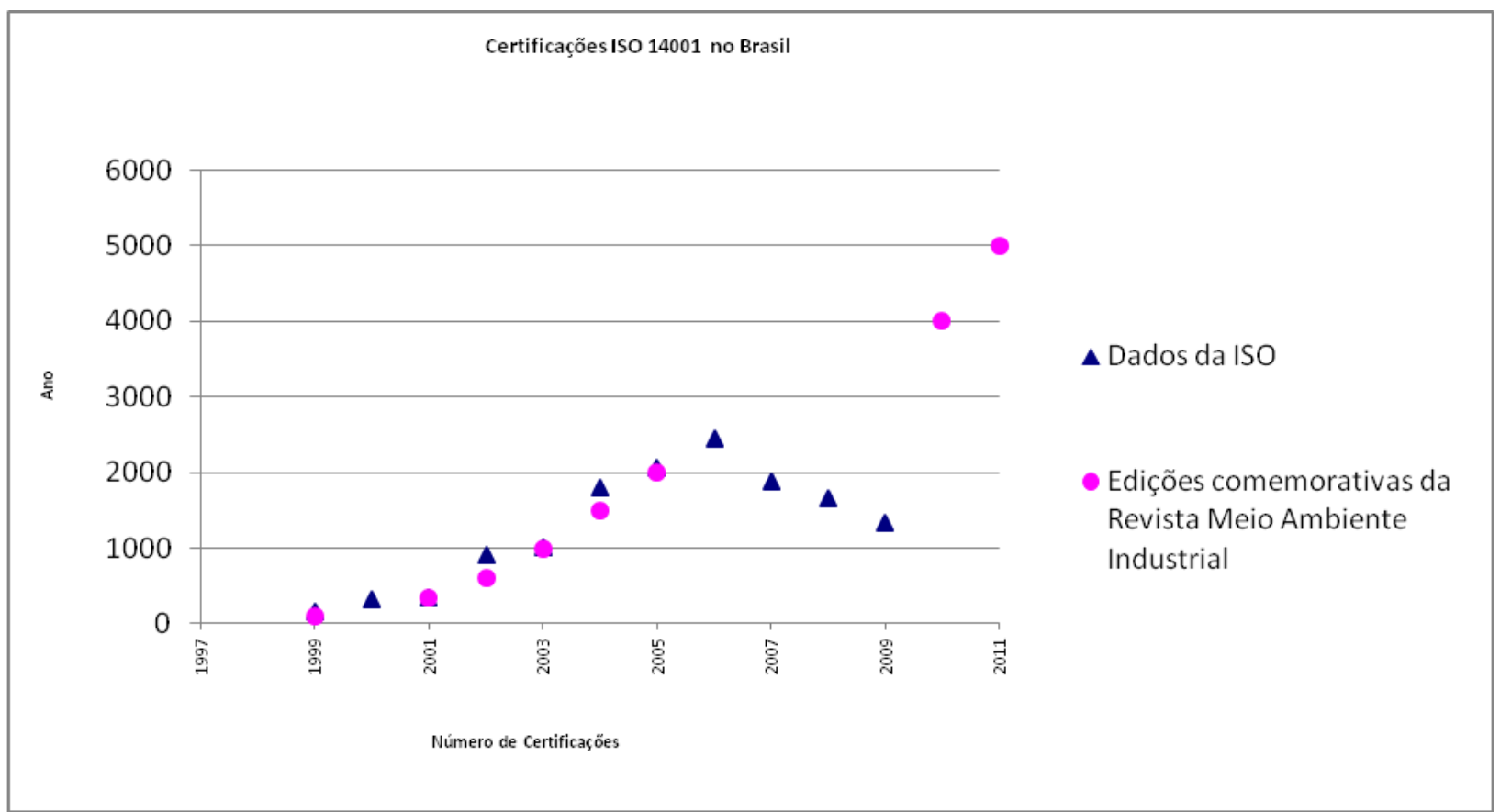

Figura 1 - Evolução das certificações ISO 14001 no Brasil.

Fonte: ISO (2009), Jucon (2010), Faverin (2011) e A evolução das certificações ISO 1400 no Brasil (2005, 2004, 2003, 2002, 2001, 1999).

Embora não haja uma exigência legal de que os organismos certificadores tornem públicas suas listas de cliente certificados, um dos preceitos do sistema de certificação de sistemas de gestão é que, ao aderir ao sistema internacional de acreditação de certificação de sistemas de gestão, os organismos certificadores devem tornar públicas as listas de clientes certificados (IAF 2011b, 2011 c). Caso esse preceito fosse obedecido, implicaria em uma redução significativa da disparidade entre os números.

Para melhor compreender a importância do acesso às informações para o processo de certificação pela norma ISO 14001 e a acreditação do organismo certificador, a revisão da literatura irá considerar os seguintes itens: $i$ ) sistemas de gestão ambiental, acreditação e certificação; ii) acreditação dos organismos certificadores, iii) certificação, confiança e transparência e $i v$ ) análise de alguns estudos anteriores, conforme disposto a seguir.

\subsection{Sistemas de gestão ambiental, acreditação e certificação}

A International Organization for Standartization (ISO) é uma organização não governamental com sede na Suíça voltada a criação e divulgação de normas voluntárias para uso internacional. Uma de suas linhas de atuação é a gestão ambiental, viabilizada com a definição de normas da família ISO 14000. As normas dessa série são publicadas em cada país pelos órgãos de normatização nacionais, sendo que no caso do Brasil isso está sob a responsabilidade da Associação Brasileira de Normas Técnicas (ABNT). Dentre as normas da 
Conflitos de transparência e confidencialidade na certificação de sistemas de gestão ambiental

série, a norma ISO 14001 é a que estabelece requisitos para sistemas de gestão ambiental a serem implantados em organizações que desejem ter uma atuação que leve em conta o meio ambiente, e que queiram demonstrar o compromisso em desenvolver uma política ambiental (ABNT, 2004). Embora a certificação do sistema de gestão não seja uma obrigação imposta pela norma ISO 14001, quase a totalidade das empresas que implementam o sistema de gestão de acordo com a norma buscam a certificação, procurando demonstrar o cumprimento da norma e atender a requisitos de mercado ou corporativos.

A certificação é efetuada por organismos certificadores ditos "de terceira parte", ou seja, órgãos avaliadores independentes, os quais podem ser instituições sem fins lucrativos ou empresas. O processo de certificação, que é baseado em uma relação contratual entre as organizações certificadora e certificada, envolve a realização de diversas auditorias, culminando com a emissão inicial do certificado, geralmente válido por três anos. Nesse período, são realizadas auditorias recorrentes, tipicamente semestrais ou anuais, dependendo do porte e da complexidade ambiental da organização.

É importante ressaltar que a ISO não é um organismo certificador, no entanto publica guias, diretrizes e normas relacionadas à avaliação de conformidade. Dentre essas, a de maior interesse para este trabalho é a ISO/IEC 17021:2011, publicada no Brasil como a norma ABNT NBR ISO/IEC 17021:2011 (Avaliação de conformidade - requisitos para organismos que fornecem auditoria e certificação de sistemas de gestão). Publicada originalmente em 2006, essa norma foi atualizada em 2011, sendo que as alterações mais significativas estão nas exigências quanto à qualificação de auditores, não havendo mudanças nas partes relativas à transparência e confidencialidade.

\subsection{Acreditação dos organismos certificadores}

Para dar maior confiabilidade ao processo, os organismos certificadores são acreditados por instituições de nível nacional. Os organismos acreditadores são, geralmente, órgãos do governo ou organizações sem fins lucrativos com atuação nacional, que impõem regras e auditam os organismos ou empresas certificadores e certificações emitidas. Tipicamente cada país tem um organismo acreditador com abrangência nacional e que segue a norma ISO/IEC 17011, que trata de requisitos para os organismos de acreditação que realizam acreditação de organismos de avaliação de conformidade.

Os organismos acreditadores se reúnem internacionalmente no Fórum Internacional de Acreditação (International Accreditation Forum - IAF), que atua tanto em certificação de 
sistemas quanto em certificação de produtos. O IAF é uma organização instituída com o objetivo de garantir que os organismos acreditadores somente validem instituições certificadoras competentes, estabelecendo acordos de reconhecimento mútuo (IAF, 2011a). Para que isso se viabilize, os organismos acreditadores que atuam em conformidade com as diretrizes do IAF devem exigir dos organismos certificadores acreditados o cumprimento dos requisitos da norma ISO/IEC 17021:2011, já mencionada anteriormente. Além dessa norma, há outras instruções, conhecidas como documentos mandatórios, que estabelecem regras específicas adicionais, tais como normas para dimensionamento das auditorias, critérios para inclusão de várias unidades num mesmo certificado, entre outras (IAF, 2011). As relações de acreditação e certificação estão resumidas na Figura 2.

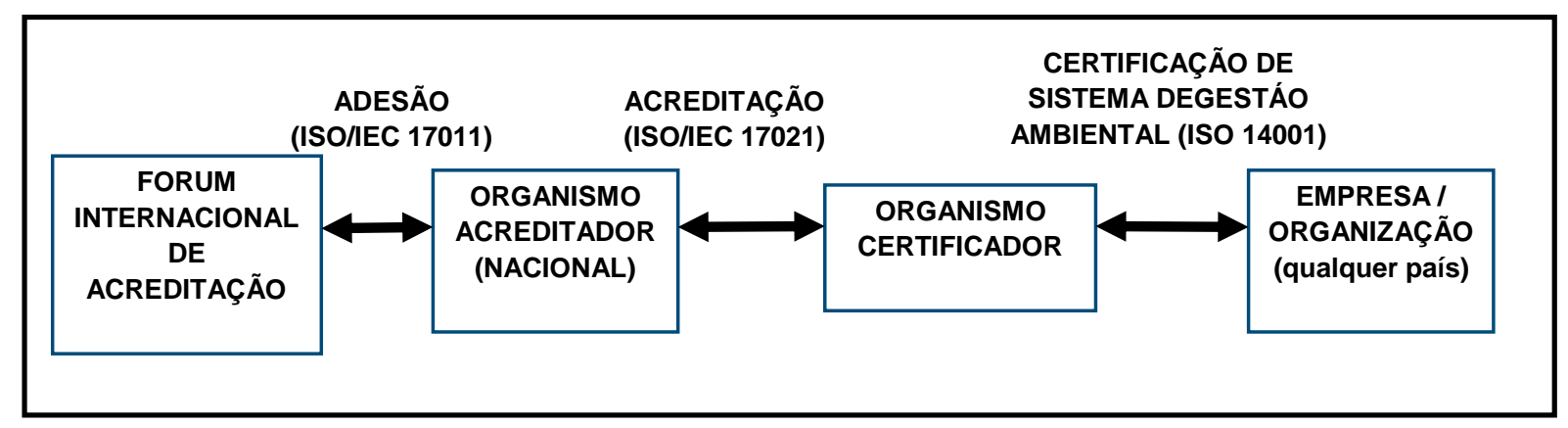

Figura 2 - Relações no sistema internacional de acreditação e certificação de sistemas de gestão ambiental e normas internacionais envolvidas.

Fonte: dos autores

\subsection{Certificação, confiança e transparência}

Com o aumento das pressões ambientais, sejam por força de instrumentos legais ou pela pressão advinda da sociedade civil, verifica-se que diversas empresas têm buscado atender essas demandas. Paloviita \& Luoma-aho (2010), por exemplo, ponderam que são os stakeholders (entendidos como incluem clientes, fornecedores e pessoas que residem nas localidades onde se desenvolvem as atividades da empresa) que estão diretamente interessados na gestão ambiental das empresas. Um problema ambiental causado por um fornecedor pode repercutir em toda a cadeia de suprimentos prejudicando a imagem do produto final junto aos stakeholders. Tendo isso em perspectiva, Johansson \& Winroth (2010) advertem para o fato de que as preocupações ambientais entraram na agenda de muitas indústrias, tornando mais complexa a formulação de estratégias produtivas. Isso demanda a implantação de uma uma cadeia verde de suprimentos (Green Supply Chain Management GSCM), com atenção aos seguintes fatores críticos: $i$ ) gestão de fornecedores; $i i)$ reciclagem de produtos; iii) envolvimento da organização e iv) gestão do ciclo de vida (Che et al., 2010; Hu \&Hsu, 2010; Goosey, 2007).

REAd | Porto Alegre - Edição 77 - N 1 - janeiro/abril 2014 - p. 31-63 
Conflitos de transparência e confidencialidade na certificação de sistemas de gestão ambiental

Entretanto, nem sempre é possível desenvolver uma GSCM, conforme atesta a pesquisa desenvolvida por Zhu et al. (2010). Esses autores verificaram que, embora indústrias japonesas tenham implantado adequadamente vários aspectos relacionados à gestão ambiental, isso ocorre mais internamente, não se verificando uma extensão disso aos clientes ou fornecedores. Em especial, as pequenas e médias empresas que integram grandes cadeias de suprimentos têm dificuldades em adotar uma gestão ambiental mais efetiva. Segundo Lee (2009), isso ocorre pelos seguintes fatores: i) escassez de recursos humanos, levando ao acúmulo de tarefas pelos membros da equipe dedicada à gestão ambiental; ii) falta de recursos financeiros e tecnológicos; iii) dificuldade de mensurar o retorno financeiro resultante dos investimentos ambientais.

Nawrocka (2008), Zhu et al. (2010) e Balkau e Sonnemann (2010) indicam que a maior eficácia na implantação de sistemas de gestão em cadeias de suprimentos é verificada quando da adoção de diretivas como a RoHS (Restriction of Certain Hazardous Substances) ou a WEEE (Waste Electrical and Electronic Equipment), adotadas pela União Européia, que impõem mudanças regionais ou globais, forçando sua extensão a toda a cadeia de suprimentos. Nawrocka (2008) lembra que, apesar do impacto de diretivas como regionais a RoHS, normas como a ISO 14001 funcionam como critério para a seleção de fornecedores. As razões dessa demanda podem ser categorizadas nos seguintes grupos: $i$ ) evitar que problemas ambientais gerados por um fornecedor contaminem a imagem da empresa ou do produto final; ii) utilizar a certificação como peça de marketing, demonstrando o compromisso com uma atuação ambiental adequada.

A confiabilidade do processo de certificação é uma decorrência da seriedade da atuação dos organismos certificadores, que devem ter sua atuação pautada pela transparência. Embora em muitos países a acreditação dos organismos certificadores não seja obrigatória, tais organismos geralmente buscam a acreditação para a emissão dos seus certificados, procurando aumentar a confiabilidade do processo de certificação. Tipicamente, os organismos acreditadores são organizações que atuam em nível nacional e supervisionam a atuação dos organismos certificadores com base em regras do IAF, conforme citado anteriormente. Uma vez signatários do acordo multilateral de reconhecimento, os organismos acreditadores devem atuar segundo as regras do fórum e exigir dos organismos certificadores acreditados o cumprimento de certas regras que foram padronizadas, entre elas o cumprimento da norma ISO/IEC 17021. 
Sobre a transparência, é interessante reproduzir a definição adotada pela Global Reporting Initiative: “... a divulgação completa de informações sobre os temas e indicadores necessários para refletir impactos e possibilitar a tomada de decisões pelos stakeholders, bem como sobre os processos, procedimentos e hipóteses usados na preparação dessa divulgação". (GRI, 2006; p. 6). Woods (2003) considera que o GRI auxilia as organizações a evidenciar as informações, facilitando sua compreensão e permitindo a obtenção de benefícios tais como: $i$ )melhora na mensuração do impacto de suas ações; ii) promoção do diálogo com os stakeholders com maior transparência e credibilidade; iii)incremento continuo de desempenho.

O Instituto Brasileiro de Governança Corporativa, por sua vez, define transparência como sendo “... o desejo de disponibilizar para as partes interessadas as informações que sejam de seu interesse e não apenas aquelas impostas por disposições de leis ou regulamentos." (IBGC 2009, p. 19). De acordo com o documento, a transparência está relacionada com um clima de confiança e não deve se restringir unicamente às informações de natureza econômicofinanceira. A norma ISO 26000, em uma abordagem similar às anteriores, define transparência como sendo "franqueza sobre decisões e atividades que afetam a sociedade, a economia e o meio ambiente (...), e o desejo de comunicá-las de forma clara, precisa, oportuna, honesta e completa" (ABNT 2010, p. 5). Por outro lado, a norma ISO 14063:2006 define a transparência como um dos princípios da comunicação ambiental, pelo qual os processos, procedimentos, métodos, fontes de dados e pressupostos usados no curso da comunicação ambiental devem estar disponíveis para todas as partes interessadas (ABNT 2009).

A importância de resgatar algumas definições sobre o termo transparência deve-se ao fato de que a norma ISO/IEC 17021 não define explicitamente esse conceito, embora a coloque entre os princípios do processo de acreditação. Essa norma esclarece que os organismos certificadores devem “... oferecer acesso público ou divulgar informações apropriadas e oportunas sobre (...) a situação da certificação de qualquer organização, a fim de obter confiança na integridade e credibilidade das certificações" (ABNT, 2011; p. 4-5). O acesso público às informações é considerado como fundamental em uma relação com as partes interessadas, implicando em uma maior transparência sobre os impactos econômicos, sociais e ambientais das ações empreendidas pelas organizações (GRI 2006). Elkington (2000), discutindo as sete revoluções da sustentabilidade, coloca a transparência como uma delas, 
Conflitos de transparência e confidencialidade na certificação de sistemas de gestão ambiental

destacando uma tendência à sua ampliação em resposta a uma maior pressão exercida pelos stakeholders diante da maior quantidade de informações disponibilizada pela mídia.

É necessário considerar, entretanto, que embora a norma ISO/IEC 17021 coloque a transparência como um dos fundamentos da acreditação, ela também coloca a confidencialidade como um dos princípios, estabelecendo que o organismo certificador deve manter confidenciais quaisquer informações privadas sobre um cliente. Aparentemente, esse conflito foi resolvido na seção 8 da referida norma, que trata das informações acessíveis ao público. Em particular, duas cláusulas devem ser destacadas:

a) Cláusula 8.1 - informações acessíveis ao público: nesta seção, é determinado que o organismo certificador deve manter acessível ao público informações sobre os processos de auditoria e certificação, e deve tornar acessíveis ao público as informações sobre certificações suspensas, concedidas ou canceladas, e deve oferecer meios para confirmação da validade de uma determinada certificação

b) Cláusula 8.3 - esta é a cláusula mais aderente ao escopo deste trabalho, pois determina que: "O organismo de certificação deve manter e tornar acessível ao público, ou fornecer quando solicitado por qualquer meio a sua escolha, uma relação de certificações válidas que deve apresentar no mínimo o nome, documento normativo pertinente, escopo, localização geográfica (por exemplo, cidade e país) para cada cliente certificado (ou a localização geográfica da sede e de quaisquer locais dentro do escopo de uma certificação multi-site)" (ABNT 2011, p. 14).

Os requisitos de confidencialidade são detalhados na cláusula 8.5 da norma ISO/IEC 17021 . Se por um lado ela requer que sobre clientes ou pessoas em particular não podem ser divulgadas a terceiros, por outro estabelece como exceções a confidencialidade as exigências de divulgação da própria norma (ABNT 2011), Um exemplo desta exceção é exatamente a cláusula 8.3, sobre a divulgação do diretório de clientes certificados.

Atualmente, com as facilidades proporcionadas pela internet, seria esperado que para maior transparência as informações mandatórias estivessem facilmente acessíveis nos sítios dos organismos certificadores.

Durante os trabalhos desta pesquisa, foram identificados pelo menos cinco organismos certificadores que atuam no Brasil sem acreditação INMETRO, operando somente com a acreditação de seus países de origem, os quais não foram incluídos no universo pesquisado. 
Alexandre de Oliveira e Aguiar \& Pedro Luiz Côrtes

\subsection{Estudos anteriores}

Conforme discutido anteriormente, praticamente nada tem sido publicado a respeito dos organismos certificadores e acreditadores, e de como a atuação dessas organizações pode contribuir ou prejudicar a eficácia dos sistemas de gestão. Por outro lado, certos estudos apontam problemas e críticas a certificação de sistemas de gestão ambiental ISO 14001.

Prakash e Potoski (2006) lembram que os críticos da norma ISO 14001 argumentam que empresas certificadas num país em que as legislações são mais flexíveis podem ter custos ambientais menores. Isso permitiria concorrência injusta entre empresas localizadas em diferentes países, mesmo que certificadas ISO 14001. Esse tipo de situação é visto com ceticismo pelo movimento ambientalista, que encararia os programas voluntários tais como a ISO 14001 como greenwash. Esses críticos também comentam que a Organização Mundial do Comércio falha em não aceitar ajustes nessa questão.

Lopez (2006) fez um balanço da implementação da ISO 14001 após dez anos e concluiu que entre os principais benefícios percebidos estão a criação de confiança e de uma boa imagem perante os clientes, o cumprimento de requisitos legais, benefícios comerciais, a satisfação de clientes, diminuição de impactos ambientais, redução de custos e benefícios para os governos. Por outro lado, aponta problemas tais como competência insuficiente de auditores internos e externos, e a falta de garantia de melhorias efetivas no desempenho ambiental (globalmente), entre outros. Por fim, em relação à certificação, a principal preocupação manifestada na pesquisa foi o surgimento de certificações não acreditadas.

Para exemplificar como a certificação ISO 14001 pode ser polêmica, é interessante mencionar Musingwini, Mbengo\&Phuti (2005), que relatam que uma mineradora de asbestos, na iminência de fechar, conseguiu a certificação ISO 14001. Isso ajudou a mineradora a manter sua operação e a perspectiva de novos mercados. Críticos diriam que a atividade de mineração de asbestos, que enfrenta forte oposição em países desenvolvidos, não deveria receber tal certificação de nenhuma forma.

Gyani (2007) comenta alguns desvios que podem ocorrer no processo de certificação de sistemas de gestão da qualidade ISO 9001 a ponto de comprometer a confiabilidade do sistema, entre elas o subdimensionamento de auditorias por parte de organismos certificadores; organismos certificadores aceitando realizar certificações em setores para os quais não contam com competência técnica em seus quadros; e o envolvimento de organismos certificadores com empresas de consultoria em sistemas de gestão. Embora os desvios indicados por Gyani (2007) sejam relativos à ISO 9001, as situações relatadas podem ser 
Conflitos de transparência e confidencialidade na certificação de sistemas de gestão ambiental

consideradas como análogas ou potencialmente muito semelhantes àquelas verificadas na ISO 14001, pois o sistema de acreditação dos organismos certificadores é basicamente o mesmo baseado na ISO/IEC 17021. Croft (2009), por exemplo, aponta que por vezes o processo foca na certificação, não nos resultados. Segundo o autor, organismos certificadores têm dificuldades para contratar auditores qualificados, o que tem levado as auditorias a se tornam mais superficiais. Quanto ao sistema de acreditação, os organismos certificadores pecam pelo excesso de burocracia, não sendo tão exigentes quanto seria necessário para tirar os maus organismos do mercado (CROFT, 2009).

A confiabilidade do sistema de avaliação de conformidade de sistemas de gestão da qualidade foi especificamente discutida em um seminário na Índia, em 2008. O Conselho de Qualidade da Índia, por meio de pesquisa com empresas certificadas, concluiu que a maioria delas não enxergava nenhum valor agregado na certificação de seu sistema da qualidade. (CALL FOR NEW INITIATIVES, 2008). Entre os problemas apontados devem ser destacados os seguintes: i) falta de um esforço por parte dos organismos certificadores em auditar a efetividade do sistema de gestão da qualidade; ii) falta de profundidade das auditorias na questão da eficácia dos processos, analisando a capacidade que os processos têm de efetivamente entregar produtos com a qualidade especificada. Diante das semelhanças entre os processos de certificação para os sistemas de gestão da qualidade e de gestão ambiental, é previsível que essas críticas sejam extensíveis aos sistemas de gestão ambiental.

\section{MÉTODOS E TÉCNICAS}

Após uma análise da produção científica sobre ISO 14001, a questão de pesquisa que se apresentou foi: "No Brasil, como é disponibilizada a informação sobre as empresas certificadas pela norma ISO 14001?". Foi estabelecido que, para responder a esta pergunta, seria necessário obter uma lista de todas as certificações ISO 14001 no Brasil junto aos organismos certificadores. Considerando que a viabilidade da obtenção dessa lista está baseada nos requisitos de transparência da ISO/IEC 17021, a resposta a essa questão de pesquisa busca atender aos seguintes objetivos de pesquisa: a) verificar quais as dificuldades em se obter as informações sobre clientes certificados ISO 14001 junto aos organismos certificadores; b) caracterizar o estado de transparência dos organismos certificadores quanto ao fornecimento da relação de empresas certificadas.

Para estudar a questão da transparência por parte dos organismos atuantes, dentro do escopo adotado pela pesquisa, foram levantadas informações junto aos organismos certificadores para

REAd | Porto Alegre - Edição 77 - N 1 - janeiro/abril 2014 - p. 31-63 
ISO 14001, que constituiu a população pesquisada. A amostra pesquisada restringiu-se aos certificadores acreditados pelo INMETRO, procurando garantir uma uniformidade de acesso aos organismos certificadores em termos de padrão de protocolo de comunicação e de idioma. Esta delimitação levou à exclusão de alguns certificadores que atuam no país exclusivamente sob acreditação estrangeira, muitas vezes fornecidas por organismos que não contam com um escritório no Brasil. Essa situação dificultaria a obtenção de informações e mesmo a delimitação do universo pesquisado.

Para operacionalizar a coleta de informações junto aos organismos certificadores, foram cumpridas as etapas mostradas a seguir, contando com o auxílio de bibliografia específica na definição das ações metodológicas (Woodside, 2010; Creswell, 2009; Severino, 2007; Malhotra et al., 2005; Marczyk, DeMatteo, \& Festinger, 2005; Cooper \& Schindler, 2003 e Hill \& Hill,2002):

i) Verificação inicial no site do INMETRO em busca de informações sobre os organismos certificadores.

ii) Pesquisa em sítios da internet de todos os organismos certificadores acreditados pelo INMETRO para certificação ISO 14001.

iii) Foram contatados os organismos certificadores por meio de uma mensagem eletrônica padrão para os seguintes casos: $a$ ) as informações não estavam disponíveis nos sites dos organismos certificadores; $b$ ) as informações obtidas nos sites dos organismos certificadores não eram completas ou estavam hospedadas em sítios de terceiros.

iv) Nos casos em que os organismos certificadores negaram a informação, o representante foi questionado quanto aos motivos da negação, e também questionado se pelo menos o número de certificações poderia ser fornecido.

v) Após a exposição dos motivos, foi apresentado o argumento da exigibilidade da informação de acordo com a ISO/IEC 17021, questionando-se como vinha sendo a postura dos organismos acreditadores quanto a essa questão. Foi solicitado também que o organismo informasse, pelo menos, o número de empresas certificadas. Esse processo de comunicação foi feito via correio eletrônico ou telefone, conforme a disponibilidade da pessoa de contato.

vi) Foi enviado um questionário por meio eletrônico para os seis organismos acreditadores citados pelos organismos certificadores, um deles o próprio INMETRO 
Conflitos de transparência e confidencialidade na certificação de sistemas de gestão ambiental

e outros cinco estrangeiros com perguntas a respeito da aplicação da ISO/IEC 17021 em particular a cláusula 8.3.

Nos casos em que a lista dos clientes certificados estava disponível na internet nos sítios dos próprios organismos certificadores (item $i$ ) e contendo todas as informações requeridas pela ISO/IEC 17021 mais a informação da acreditação, o processo foi dado como completo.

Para o item iii, a mensagem eletrônica foi direcionada para a pessoa cadastrada no sítio do INMETRO como contato do organismo certificador. Nos casos em que não houve resposta em até uma semana, foi iniciado processo de contato telefônico até que se obtivesse o acesso a pessoa-chave para obtenção das informações. Em alguns casos a informação foi obtida e o processo encerrado.

\section{RESULTADOS DA PESQUISA}

Os resultados apresentados a seguir foram obtidos de acordo com as etapas indicadas no item 3. Métodos e técnicas.

\subsection{Informações disponíveis no sítio do INMETRO}

O site do INMETRO mostrou 20 organismos certificadores acreditados para certificação ISO 14001 e 291 empresas certificadas. Ao clicar no nome da empresa, aparecem detalhes do certificado, incluindo endereço, validade, escopo e nomes para contato. Uma vez que a ISO/IEC 17021 permite que o organismo certificador forneça o acesso por qualquer meio que julgar adequado, esta forma serve para cumprir essa, desde que os dados estejam atualizados.

\subsection{Informações disponíveis nos sítios dos organismos certificadores}

Dos 20 organismos certificadores, dois deles colocam as informações sobre seus clientes certificados com acesso fácil e completo a lista de certificados ISO 14001, sendo confirmado um total de 206 certificações. Da relação inicial contendo 20 organismos certificadores, 18 foram elegíveis para as fases posteriores da pesquisa, pelos seguintes motivos:

a) Dois organismos certificadores apresentam as informações, mas elas não são facilmente pesquisáveis, impossibilitando a construção de uma lista. Em um dos casos a lista em si podia ser construída, mas a informação da localização geográfica não foi obtida. 
b) Um organismo certificador apresentava uma lista de clientes certificados em seu próprio site diferente daquela constante no site do INMETRO, por isso a informação não foi aceita nesta etapa.

c) Quinze organismos certificadores não apresentavam a informação no próprio sítio. Um deles apresenta lista de certificados no sítio corporativo, que está em língua estrangeira e, tendo em perspectiva a transparência, a lista não foi considerada.

d) Note-se que no sítio do INMETRO foram encontradas listas de clientes certificados de sete organismos certificadores e para treze dos organismos acreditados a pesquisa retornou vazia.

Vários organismos oferecem em seu sítio uma ferramenta para verificação de situação de uma empresa certificada específica, o que não foi considerado aceito para fins do cumprimento da cláusula 8.3 da norma ISO IEC 17021, conforme interpretação do CASCO.

\subsection{Solicitação das listas de clientes certificados}

Da relação inicial de 20 organismos certificadores, 18 precisaram ser contatados por mensagem eletrônica, pois não apresentaram em seus sítios as informações sobre seus clientes certificados. Os resultados desses contatos foram os seguintes:

a) Dois organismos certificadores enviaram as listas conforme solicitado, sendo um deles imediatamente e outro após várias tentativas, e um deles informou que apesar de acreditado ainda não tem nenhuma certificação no Brasil.

b) O organismo certificador que tinha informações no seu próprio sítio que eram diferentes das que constavam no sítio do INMETRO esclareceu a diferença

c) Um organismo certificador informou que a lista no sítio do INMETRO poderia ser considerada atualizada.

d) Um organismo certificador esclareceu como obter a informação sobre localização geográfica das empresas certificadas no próprio sítio da internet, com um passo adicional de pesquisa.

e) Um dos organismos respondeu que o sítio do INMETRO era a fonte a ser consultada, no entanto não respondeu frente ao questionamento de que o sítio não indicava nenhuma certificação, embora houvesse divulgação de divulgasse exemplos de clientes certificados ISO 14001 por este organismo.

f) Dois organismos certificadores não responderam ou disseram que estavam verificando internamente, mas nunca responderam definitivamente. 
Conflitos de transparência e confidencialidade na certificação de sistemas de gestão ambiental

g) Nove organismos certificadores explicitamente negaram-se a oferecer a lista de clientes certificados. Um deles ofereceu uma lista de clientes certificados com localização geográfica, mas sem especificar em que norma, misturando gestão ambiental com outras certificações, e sem especificar o escopo.

h) As certificações confirmadas pelos cinco organismos certificadores que enviaram ou esclareceram suas listas totalizam 556 certificações.

Ao final desta etapa, 11 organismos ainda relutavam em apresentar a relação de empresas certificadas, sendo argüidos sobre os motivos dessa recusa, conforme explicitado na descrição dos resultados da próxima fase.

\subsection{Solicitação de esclarecimento sobre o motivo da negação}

Entre os organismos certificadores que se negaram a oferecer a lista de clientes certificados e responderam ao questionamento sobre as razões, a razão mais comumente apresentada foi a da confidencialidade, seguida pela competitividade, conforme relação a seguir:

a) Três organismos argumentaram somente a confidencialidade de informações dos clientes.

b) Um deles argumentou tratar-se de uma política corporativa, e não se dispôs a explicar mais que isso.

c) Um argumentou confidencialidade das informações dos clientes e os aspectos de competitividade.

d) Um deles argumentou diretamente com o tema da necessidade de proteger a competitividade, ou seja, evitar ataques da concorrência

e) Um deles argumentou confidencialidade de dados dos clientes e regras internas.

f) Um deles argumentou que não é obrigatório fornecer a informação,

g) Um deles argumentou confidencialidade de dados de clientes e regras do INMETRO, incluindo ISO/IEC 17021.

Após esta etapa, nove organismos ainda relutavam em apresentar informações sobre as empresas certificadas, sendo nomeáveis para a fase posterior.

Nesta etapa, dois dos organismos certificadores forneceram não uma lista, mas a quantidade de certificados válidos emitidos, num total de 137 certificados. 
Alexandre de Oliveira e Aguiar \& Pedro Luiz Côrtes

\subsection{Questionamento quanto a ISO/IEC 17021}

Com a apresentação, para os organismos certificadores ainda relutantes, do argumento da exigibilidade da informação de acordo com a ISO/IEC 17021, constatou-se o seguinte comportamento:

a) Dois deles mudaram de postura inicial e informaram as certificações. $O$ total de certificações informadas foi 172 .

b) Dois deles mantiveram sua postura, sob o argumento da competitividade, evitando ataques de concorrentes.

c) Um manteve sua postura, sob o argumento de que não há obrigação de informar expressa na norma ISO/IEC 17021.

d) Quatro não responderam.

\subsection{Balanço geral}

Dez dentre os vinte organismos certificadores pesquisados informaram a relação de clientes certificados ISO 14001, sendo que o total informado foi de 934 certificações. Dois dos organismos que não forneceram a lista informaram a quantidade de certificados, que somam 137 certificados, totalizando 1071 certificações confirmadas.

Dentre os dez organismos que informaram a lista de clientes certificados, em sete casos a informação do sítio do INMETRO não contempla todas as certificações informadas, sendo que em três casos o sítio informava que não havia registro de certificações. Para os dois organismos que informaram somente a quantidade de certificados, o sítio também informa que não há certificados registrados. Por outro lado, o sítio do INMETRO indica certificações num total de 126 para três organismos que não quiseram informar nem a relação e nem o número de certificados. O sítio indica que em todos os casos é utilizada a marca de acreditação INMETRO, mas de acordo com os resultados desta pesquisa não há garantias de que sejam as únicas certificações, e também não há garantias de que não haja certificações suspensas ou canceladas que não tenham sido atualizadas.

\subsection{Levantamento junto a organismos acreditadores}

Foi enviado questionário por meio eletrônico para seis organismos acreditadores (citados pelos organismos certificadores), em busca de informações sobre as empresas certificadas e da sua atuação frente a temática da transparência no contexto da ISO/IEC 17021. Todos eles afirmaram que as ferramentas de verificação de validade de certificado, disponibilizadas nos 
Conflitos de transparência e confidencialidade na certificação de sistemas de gestão ambiental

sítios dos organismos certificadores, não era aceita para cumprimento da cláusula 8.3 da ISO/IEC 17021, embora cumprisse a cláusula 8.1.

Todos também confirmaram, da mesma forma, que em suas auditorias periódicas nos organismos certificadores, questionam sobre as solicitações de informações sobre empresas certificadas. Igualmente, todos os acreditadores informaram que não mantêm listas dos certificados emitidos por seus organismos certificadores acreditados. No caso específico do INMETRO, de acordo com o representante, embora a lista esteja hospedada em seu sítio, a atualização foi delegada a um comitê da ABNT.

Ao serem questionados, todos os organismos acreditadores confirmaram a inclusão de certificações emitidas em outros países em suas auditorias. Da mesma forma, todos foram unânimes em dizer que realizam auditorias-testemunho em outros países.

Sobre a data de validade do certificado, um dos representantes informou que essa informação originalmente deveria constar na cláusula 8.3 da ISO/IEC 17021, mas foi retirada da lista de exigências exatamente para derrubar a argumentação dos organismos certificadores que não queriam publicar as listas devido aos ataques dos concorrentes, que aconteciam predominantemente próximo a data de validade dos certificados.

\section{DISCUSSÃO}

$\mathrm{Na}$ revisão da literatura, empreendida durante o desenvolvimento desta pesquisa, ficou evidenciada a carência de estudos específicos sobre o grau de transparência em sistemas e processos de certificação. Considera-se, entretanto, que a evidenciação de informações, conforme preconizada pela norma ISO/IEC 17021, possa ser considerada - dentro de uma perspectiva mais ampla - no âmbito da Responsabilidade Social Empresarial (RSE), diante das repercussões que podem ter junto aos stakeholders, demonstrando a transparência do processo de certificação pela ISO 14001. Essa importância da evidenciação e da transparência das informações tem sido atestada por diferentes pesquisas, com repercussões sempre positivas para as empresas e para os stakeholders.

Apesar dessa importância, fica claro que a cláusula 8.3 da ISO/IEC 17021 não está completamente implantada, o que demonstra uma falha na aplicação do conceito de transparência pelos organismos certificadores acreditados pelo INMETRO. Os resultados obtidos são preocupantes, na medida em que três dos organismos não chegaram a responder a primeira pergunta da pesquisa, nem mesmo com um "não". Apenas dez, dentre os vinte organismos certificadores contatados, informaram sua lista de clientes certificados, em algum 
ponto do processo de comunicação. É necessário considerar, entretanto, que dois organismos apenas forneceram essa informação após a argumentação de que ISO/IEC 17021 determinava isso. Note-se que esta é uma argumentação para iniciados, o que permite prospectar que em caso de uma consulta feita por leigo a lista não teria sido fornecida.

Dois dos organismos certificadores, por outro lado, argumentaram que a ISO/IEC 17021 não exige que as informações solicitadas fossem disponibilizadas. A partir dessa informação, duas possibilidades podem ser consideradas: $i$ ) existe um desconhecimento das regras do sistema de certificação por parte dos interlocutores; ii) os organismos utilizaram de má fé ao utilizarem uma interpretação errônea da norma. $\mathrm{O}$ atendimento a políticas corporativas foi o argumento utilizado por outros dois organismos certificadores, mesmo que as bases dessas políticas não tenham sido explicitadas. Esse também é um comportamento errôneo, pois a submissão à norma ISO/IEC 17021 é um requisito básico para a atuação de um órgão certificador. Comportamentos desse tipo, onde a norma é interpretada ao sabor das conveniências ou submete-se às políticas internas foram previstos por Tinoco \& Robles (2006). Esses autores verificaram que, mesmo as organizações que têm políticas e estratégias bem definidas com relação à gestão ambiental, restringem seu comportamento à obediência aos princípios legais, ou nem isso conforme evidenciado pelo comportamento de alguns organismos certificadores.

Em vários momentos, os representantes dos organismos certificadores buscavam refúgio no argumento da ferramenta de verificação individual de certificados. No entanto, decisão do Comitê Técnico do IAF sobre a interpretação desta questão deixou claro que os organismos acreditadores não podem aceitar tal ferramenta para cumprimento da cláusula 8.3 sobre o diretório de clientes certificados (IAF, 2011c).

Sobre os possíveis motivos para não fornecer as informações solicitadas:

a) Sigilo de informações de clientes: esse sigilo não é consistente com os requisitos da ISO/IEC 17021. Nos casos em que esse motivo foi informado, pode ter havido engano do representante ou foi um artifício utilizado para não revelar os reais motivos, ou tentar fazer o interessado desistir de obter a lista de certificados.

b) Evitar ataque de concorrentes: este é um motivo plausível, embora esteja em conflito com a ISO/IEC 17021. Pode existir sim um sentimento no mercado de que a certificação seja uma espécie de commodity, com a escolha do organismo certificador ocorrendo em função do preço.

REAd | Porto Alegre - Edição 77 - N 1 - janeiro/abril 2014 - p. 31-63 
Conflitos de transparência e confidencialidade na certificação de sistemas de gestão ambiental

c) Receio de exposição: caso um cliente se envolva em algum escândalo ambiental, existe o risco de o organismo certificador acabar envolvido também. Embora essa argumentação não tenha sido utilizada por nenhum organismo certificador, é uma possibilidade a ser considerada e está aderente às considerações levantadas por Newell \& Frynas (2007) e Jackson \& Apostolakou (2009) sobre as políticas de relações públicas que buscam reduzir críticas e capitalizar ações positivas.

Fica evidenciada a deficiência dos organismos certificadores na aplicação do fundamento da transparência e na aplicação da cláusula 8.3 da norma ISO/IEC 17021. Embora isso possa ser tratado pelas auditorias realizadas pelos organismos acreditadores, o levantamento efetuado mostra que isso não vem sendo eficaz. Dos dez organismos que não deram as informações, sete argumentaram que os organismos acreditadores têm aceitado esta postura. Sendo isso verdade, essa postura indicaria uma condescendência que não pode ser aceita no âmbito do cumprimento das regras contratadas da certificação, e nem da ética requerida para a transparência do processo de certificação. A causa declarada para essa postura que tem mais presença é a competição entre certificadores. Pode-se também estudar como uma possível causa a tentativa de não envolvimento com possíveis problemas ambientais provocados por uma empresa certificada.

De qualquer forma, essa prática é difícil de auditar, pois caso o organismo certificador não queira relatar pedidos de informação sobre clientes certificados, é fácil escondê-los dos organismos acreditadores, bastando não registrar os telefonemas ou apagar os e-mails recebidos. Mesmo que esse estratagema não seja usado, é difícil para um auditor localizar a evidência ativamente sem a ajuda do próprio auditado. A única forma alternativa seria uma denúncia ao organismo acreditador, por parte dos interessados nas informações.

É necessária uma reflexão sobre o acesso público a informações desse tipo, dentro do que propõem Jardim, Silva, \& Nharreluga (2009). Considera-se que uma política de informação, dentro de um contorno mais específico, deverá contemplar o acesso livre a fontes de informação relevantes na Internet, possibilitando que o uso do conhecimento possa gerar novos saberes (FREIRE, 2008; CARVALHO \& KANISKI, 2000). Essa é uma perspectiva também preconizada por Werthein (2000), que considera necessário ampliar o volume de informação de qualidade disponibilizada ao público por meio da Internet.

Quanto às informações do site do INMETRO, mesmo com relação às empresas certificadas sob sua acreditação, carecem de confiabilidade quanto a sua abrangência e atualização. Dois dos representantes dos organismos certificadores relataram dificuldades operacionais para 
atualizar e desistiram de participar da sistemática. Isso remete ao trabalho de Marcondes \& Sayão (2001), onde são discutidas soluções que permitem o acesso unificado a recursos informacionais heterogêneos disponibilizados em diversas redes. Dentro dessa perspectiva, convém mencionar a existência de um banco de dados público de empresas certificadas de acordo com o regime europeu EMAS, que inclui informações completas sobre as empresas certificadas. Mesmo sendo de uso voluntário, diversas empresas aderiram a esse sistema, pois sabem que as informações sobre as certificações serão publicadas.

\section{CONCLUSÕES}

Um número pequeno de organismos certificadores que fazem certificações de sistema de gestão ISO 14001 no Brasil tem disponibilizado a relação de clientes certificados de maneira aberta na Internet. Uma parte um pouco maior disponibilizou a relação de clientes sob demanda. Em alguns casos isso provavelmente não teria sido fornecido a um leigo, dado que a informação solicitada só foi fornecida frente a argumentação baseada na norma ISO/IEC 17021. Aproximadamente a metade dos organismos certificadores se recusou a fornecer a lista de clientes certificados, o que é exigido pela norma ISO/IEC 17021. Fica dessa forma evidenciado que nem todos os organismos certificadores estão praticando o valor transparência quando o assunto é a divulgação de informações e estatísticas sobre clientes certificados, sob o principal argumento da proteção contra a concorrência. Isso pode reduzir o nível de confiança que se tem no sistema de certificações acreditadas, o que pode levar a um crescimento de certificações não acreditadas. Já existe registro desse fenômeno em âmbito internacional, embora ainda haja uma carência de estudos sobre isso no Brasil. Não foi objeto desse estudo a caracterização do tipo de organismo certificador que disponibiliza ou não as informações, até porque informações como participação no mercado, natureza jurídica e outras de interesse nem sempre estão disponíveis.

Ao longo deste trabalho puderam ser obtidas as informações básicas sobre 934 unidades com certificação de sistemas de gestão ambiental ISO 14001 no Brasil, incluindo nome, localização geográfica e escopo da certificação. Como alguns organismos certificadores que não informaram a lista se dispuseram a informar as quantidades, chega-se ao número conformado de 1071 certificações. Tal resultado é incompleto porque nem todos os organismos certificadores ofereceram as informações solicitadas, mas mostra um número mínimo confirmado. Se os resultados relatados por Jucon (2010) estiverem corretos, isso indica que os líderes de mercado não estão dispostos a informar sua lista de clientes 
Conflitos de transparência e confidencialidade na certificação de sistemas de gestão ambiental

certificados, uma vez que a lista representaria menos de $20 \%$ das certificações ISO 14001 no Brasil.

\section{CONSIDERAÇÕES FINAIS: LIMITAÇÕES E OPORTUNIDADES DE PESQUISA}

Algumas das limitações da pesquisa constituem oportunidades para estudos posteriores. O tema pesquisado poderia ser mais aprofundado, incluindo organismos certificadores que atuam no Brasil sem a acreditação do INMETRO, até para verificar se há diferenças em sua atitude quanto a transparência das certificações. Quanto a possibilidade de generalização, o estudo trata basicamente da realidade do mercado brasileiro. Não se pode, portanto, inferir que as mesmas atitudes e motivos para não praticar a transparência estejam presentes em outros países.

O estudo atual não avaliou as políticas corporativas de governança e estruturas similares dos organismos certificadores, verificando seu discurso contra a prática de comunicação. O estudo poderia prospectar novas formas de obter as informações, incluindo verificando as estatísticas sobre empresas certificadas no Brasil. Por último, considera-se oportuno estudar o ambiente competitivo dos organismos certificadores a fim de determinar suas características quanto a qualidade do serviço, valor percebido e preços praticados.

\section{REFERÊNCIAS}

[ABNT] ASSOCIAÇÃO BRASILEIRA DE NORMAS TÉCNICAS. NBR ISO 14001. Sistemas da gestão ambiental - Requisitos com orientações para uso. ABNT: Rio de Janeiro, 2004.

[GRI] GLOBAL REPORTING INITIATIVE. Diretrizes para relatório de sustentabilidade - versão 3.0. Disponível em: <http://www.globalreporting.org/NR/rdonlyres/4855C490A872-4934-9E0B-8C2502622576/5288/DiretrizesG3.pdf $>$

[IAF] - INTERNATIONAL ACCREDITATION FORUM (n.d.). About IAF. Disponível em: $<$ http://www.iaf.nu/>. Acesso em 12 Jul 2011.

[IBGC] INSTITUTO BRASILEIRO DE GOVERNANÇA CORPORATIVA. Código das melhores práticas de governança corporativa. São Paulo: IBGC, 2009. Disponível em: $\langle$ http://www.ibgc.org.br/Download.aspx?Ref=Codigos\&CodCodigo=47>. Acesso em 26 Ago 2011. 
[INMETRO] INSTITUTO NACIONAL DE NORMALIZAÇÃO. Empresas Certificadas. Disponível em: http://www.inmetro.gov.br/gestao14001/login.asp?chamador=INMETRO14. Acesso em 25 Jun 2011.

[ISO] INTERNATIONAL ORGANIZATION FOR STANDARTIZATION. The ISO survey of Certifications 2009. ISO: Genebra, 2010. [CD-ROM].

ABNT NBR ISO 14063 Gestão ambiental — Comunicação ambiental Diretrizes e exemplos. ABNT: Rio de Janeiro, 2009.

ABNT NBR ISO 26000 - Diretrizes sobre responsabilidade social. ABNT: Rio de Janeiro, 2010.

ABNT NBR ISO/IEC 17011. Avaliação de conformidade - Requisitos gerais para organismos de acreditação que realizam acreditação de organismos de avaliação de conformidade. ABNT: Rio de Janeiro, 2005.

ABNT NBR ISO/IEC 17021 - Avaliação de conformidade - Requisitos para organismos que fornecem auditoria e certificação de sistemas de gestão. ABNT: Rio de Janeiro, 2011.

2011.[2011a].

About ISO. Retrieved from http://www.iso.org/iso/about.htm on $12 \mathrm{Jul}$

Discussion Paper (Decision Log 11/07/17). [Relatório de discussão do comitê técnico do IAF, referente a questão de transparência e conformidade com as cláusulas 8.1 e 8.3 da ISO/IEC 17021] (2011b).

Objectives and structure of CASCO. Retrieved from

http://www.iso.org/iso/resources/conformity_assessment/objectives_and_structure_of_casc o.htm on $12 \mathrm{Jul} 2011$. [2011b].

.Structure of the IAF MLA and list of IAF endorsed normative documents. Issue 5, Version 2. (IAF PR 4: 2011). Disponível em: 〈http://www.iaf.nu/> Acesso em 8 Set 2011.(2011c).

About IAF. Disponível em <http://www.iaf.nu/> Acesso em 12 Jul 2011 (2011 a).

A EVOLUÇÃO DAS CERTIFICAÇÕES ISO 14001 NO BRASIL. Revista Meio Ambiente Industrial. Edição 55 Maio/Junho de 2005. 
Conflitos de transparência e confidencialidade na certificação de sistemas de gestão ambiental

A EVOLUÇÃO DAS CERTIFICAÇÕES ISO 14001 NO BRASIL. Revista Meio Ambiente Industrial. Edição 49 Maio/Junho de 2004.

A EVOLUÇÃO DAS CERTIFICAÇÕES ISO 14001 NO BRASIL. Revista Meio Ambiente Industrial. Edição 43 n 42 Maio/Junho de 2003.

A EVOLUÇÃO DAS CERTIFICAÇÕES ISO 14001 NO BRASIL. Revista Meio Ambiente Industrial. Edição 32 nº 31 Julho/Agosto de 2002.

A EVOLUÇÃO DAS CERTIFICAÇÕES ISO 14001 NO BRASIL. Revista Meio Ambiente Industrial. Edição 19 nº 18 Julho/Agosto de 2001.

APPOLINÁRIO, F. Dicionário de metodologia científica: um guia para a produção do conhecimento científico. São Paulo: Atlas, 2004.

ARVIDSSON, S. Communication of Corporate Social Responsibility: A Study of the Views of Management Teams in Large Companies. Journal of Business Ethics, 96, n. 3, 2010. 339-354.

ÁVILA, G. J.; PAIVA, E. L. Processos operacionais e resultados de empresas brasileiras após a certificação ambiental ISO14001. Gestão \& Produção v.13, n.3, p.475-487, set.-dez. 2006.

BALKAU, F.; SONNEMANN, G. Managing sustainability performance through the valuechain. Coporate Governance, 10, n. 1, 2010. 46-58.

CALL for new initiatives to enhance credibility of certification process. Quality India. Vol2 n. 5. Disponível em: http://www.qcin.org/nbqp/qualityindia/Vol-2-

No5/industry_page_22_25.php. Acesso em 25/06/2011.

CAMPOS, L. M. S.; GRZEBIELUCKAS, C; SELIG, P. M. As empresas com certificação ISO 14001 são mais rentáveis? Uma abordagem em companhias abertas no Brasil. Revista Eletrônica de Administração - REAd. Edição 62 Vol 15 Nº 1 jan-abr 2009.

CARVALHO, I. C. L.; KANISKI, A. L. A sociedade do conhecimento e o acesso à informação: para que e para quem? Ciência da Informação, 29, n. 3, 2000. 33-39.

CHE, Z.-H.; CHIANG, Y.-A; TU, C; CHIANG, C-J. A Supplier Selection Model for Product Design Changes. International Journal of Electronic Business Management, 8, n. 1, 2010. 20-30. 
COOPER, D. R.; SCHINDLER, P. S. Métodos de pesquisa em administração. $7^{\mathrm{a}}$. ed. Porto Alegre: Bookman, 2003.

CORDEIRO J, ZHU Q, SARKIS J. International and domestic pressures and Chinese organizational responses to greening. Academy Of Management Annual Meeting Proceedings [serial online]. August 2009;:1-6. Available from: Business Source Complete, Ipswich, MA. Accessed December 12, 2011.

CRESWELL, J. W. Research Design: Qualitative, Quantitative, and Mixed Methods Approaches. Thousand Oaks: SAGE, 2009.

CROFT, N. Future trends for ISO 9001 and accredited certification. Disponível em: <http://www.iram.org.ar/eventos/ISO-JTCG/Presentaciones/Nigel_Croft.pdf>. Acesso em 25 Jun 2011.

DELMAS, M.; BLASS, D. Measuring Corporate Environmental Performance: the Trade-Offs of Sustainability Ratings. Business Strategy and the Environment, 19, n. 4, 2010. 245-260.

DELMAS, M.; MONTIEL, I. The Diffusion of Voluntary International Management Standards: Responsible Care, ISO 9000, and ISO 14001 in the Chemical Industry. The Policy Studies Journal, Vol. 36, No. 1, 2008.

DHALIWAL, D. S. et al. Voluntary Nonfinancial Disclosure and the Cost of Equity Capital: The Initiation of Corporate Social Responsibility Reporting. The Accounting Review, 86, n. 1, 2011. 59-100.

FARONI, W. et al. A contabilidade ambiental em empresas certificadas pelas normas ISO 14001 na região metropolitana de Belo Horizonte-MG. Revista Árvore, 34, n. 6, 2010. 11191128.

FAVERIN, V. Homenagem às empresas sustentáveis comemora marca de cinco mil certificações e suscita momento histórico do setor ambiental brasileiro. Revista Meio Ambiente Industrial. Edição Especial Ano XVI Edição 91 Maio/Junho de 2011.

FREIRE, G. H. D. A. Construção participativa de instrumento de política pública para gestão e acesso à informação. Perspectivas em Ciência da Informação, 13, n. 3, 2008. 195-207.

FRYXELL. G. E. http://www.sciencedirect.com/science/article/pii/S0301479704000283 COR1\#COR1; CHUNG, S. S.; CARLOS W.H LO, W. H. C. Does the selection of ISO 14001 registrars matter? Registrar reputation and environmental policy statements in China. Journal of Environmental Management Volume 71, Issue 1, May 2004, Pages 45-57 oi:10.1016/j.jenvman.2004.01.005. 
Conflitos de transparência e confidencialidade na certificação de sistemas de gestão ambiental

GOOSEY, M. Implementation of the RoHS directive and compliance implications for the PCB sector. Circuit World, 33, n. 1, 2007. 47-50.

GYANI, GIRDHAR J. Crisis of Credibility Quality system certification worldwide. Quality Digest 8/jul/2007. Disponível em: <http://www.qualitydigest.com/inside/standardsarticle/crisis-credibility>. Acesso em 25/06/2011.

HERAS-SAIZARBITORIA, I.; MOLINA-AZORIN, J. F.; DICK, G. P. M. ISO 14001 certification and financial performance: selection-effect versus treatment-effect. Journal of Cleaner Production, 19, n. 1, 2011. 1-12.

HILL, M. M.; HILL, A. Investigação por questionário. 2a . ed. Lisboa: Silabo, 2002.

HU, A. H.; HSU, C.-W. Critical factors for implementing green supply chain management practice: an empirical study of electrical and electronics industries in Taiwan. Management Research Review, 33, n. 6, 2010. 586-608.

Jabbour C. Non-linear pathways of corporate environmental management: a survey of ISO 14001-certified companies in Brazil. Journal Of Cleaner Production [serial online]. August 2010;18(12):1222-1225. Available from: Academic Search Premier, Ipswich, MA. Accessed December 12, 2011.

JACKSON, G.; APOSTOLAKOU, A. Corporate Social Responsibility in Western Europe: An Institutional Mirror or Substitute? Journal of Business Ethics, 94, n. 3, 2009. 371-394.

JARDIM, J. M.; SILVA, S. C. D. A.; NHARRELUGA, R. S. Análise de políticas públicas: uma abordagem em direção às políticas públicas de informação. Perspectivas em Ciência da Informação, 14, n. 1, 2009. 2-22.

JOHANSSON, G.; WINROTH, M. Introducing environmental concern in manufacturing strategies: implications for the decision criteria. Management Research Review, 33, n. 9, 2010. 877-899.

JUCON S. A evolução da certificação em conformidade com a norma ISO 14001 e o fortalecimento da sustentabilidade empresarial. Revista Meio Ambiente Industrial. Edição Especial. Ano XV - Edição 85 - maio/junho de 2010.

KAZILIUNAS, A. Problems of auditing using quality management systems for sustainable development of organizations. Technological and Economic Development of Economy, 14, n. $1,2008.64-75$. 
LEE, K.-H. Why and how to adopt green management into business organizations? The case study of Korean SMEs in manufacturing industry. Management Decision, 47, n. 7, 2009. 1101-1121.

LOPEZ, S. 10th Anniversary of ISO 14001: Did the environmental management standard save the world or was it just another bureaucratic system? [Thesis for the fulfillment of the Master of Science in Environmental Management and Policy] Lund, Sweden, October 2006. Disponível em:

$<$ http://lup.lub.lu.se/luur/download?func=downloadFile\&recordOId=1326527\&fileOId=1326 528>. Acesso em: 25 Jun 2011.

MALACRIDA, M. J. C.; YAMAMOTO, M. M. Governança corporativa: nível de evidenciação das informações e sua relação com a volatilidade das ações do Ibovespa.

Revista Contabilidade e Finanças, 17, n. spe, 2006. 65-79.

MALHOTRA, N. K. E. A. Introdução à pesquisa de marketing. São Paulo: Pearson Prentice Hall, 2005.

MARCONDES, C. H.; SAYÃO, L. F. Integração e interoperabilidade no acesso a recursos informacionais eletrônicos em C\&T: a proposta da Biblioteca Digital Brasileira. Ciência da Informação, 30, n. 3, 2001. 24-33.

MARCZYK, G. R.; DEMATTEO, D.; FESTINGER, D. Essentials of Research Design and Methodology. Hoboken: John Wiley \& Sons, 2005.

MIJATOVIC, I.; STOKIC, D. The Influence of Internal and External Codes on CSR Practice: The Case of Companies Operating in Serbia. Journal of Business Ethics, 94, n. 4, 2010. 533 552.

MITCHELL, C. G.; HILL, T. Corporate Social and Environmental Reporting and the Impact of Internal Environmental Policy in South Africa. Corporate Social Responsibility and Environmental Management, 16, n. 1, 2009. 48-60.

MORETTI, G. N.; SAUTTER, K. D.; AZEVEDO, J. A. M. ISO 14001: implementar ou não? Uma proposta para a tomada de decisão. Engenharia Sanitaria e Ambiental, 13, n. 4, 2008.

MUSINGWINI; C. MBENGO, I; PHUTI, D. Challenges and Criticisms of ISO 14001 Certification of Two Asbestos Mines The 19th International Mining Congress and Fair of Turkey. IMCET2005, İzmir, Turkey, June 09-12, 2005. Disponível em: <http://www.maden.org.tr/resimler/ekler/5a0ce8200cf39c3_ek.pdf $>$. Acesso em 25 Jun 2011. 
Conflitos de transparência e confidencialidade na certificação de sistemas de gestão ambiental

NAWROCKA, D. Environmental Supply Chain Management, ISO 14001 and RoHS. How Are Small Companies in the Electronics Sector Managing? Corporate Social Responsibility and Environmental Management, 15, n. 6, 2008. 349-360.

NEWELL, P.; FRYNAS, J. G. Beyond CSR? Business, poverty and social justice: an introduction. Third World Quarterly, 28, n. 4, 2007. 669 - 681.

OLIVEIRA, O. J. D.; PINHEIRO, C. R. M. S. Implantação de sistemas de gestão ambiental ISO 14001: uma contribuição da área de gestão de pessoas. Gestão \& Produção, 17, n. 1, 2010. 51-61.

OLIVEIRA, O. J. D.; SERRA, J. R. Benefícios e dificuldades da gestão ambiental com base na ISO 14001 em empresas industriais de São Paulo. Produção, 20, n. 3, 2010. 429-438.

ORSATO, R. J. Posicionamento ambiental estratégico. Identificando quando vale a pena investir no verde. Revista Eletrônica de Administração - REAd. Edição Especial 30 Vol. 8 No. 6, nov-dez 2002.

PALOVIITA, A.; LUOMA-AHO, V. Recognizing definitive stakeholders in corporate environmental management. Management Research Review, 33, n. 4, 2010. 306-316.

POMBO, F. R.; MAGRINI, A. Panorama de aplicação da norma ISO 14001 no Brasil. Gestão \& Produção, 15, n. 1, 2008. 1-10.

PRAKASH A., POTOSKIM. Racing to the bottom? Trade, environmental governance, and ISO 14001. American Journal of Political Science. Volume 50, Issue 2, pages 350-364, April 2006. DOI: 10.1111/j.1540-5907.2006.00188.x

ROHRICH, S. S.; CUNHA, J. C. D. A proposição de uma taxonomia para análise da gestão ambiental no Brasil. Revista de Administração Contemporânea, 8, n. 4, 2004. 81-97.

RUZEVICIUS, J. The Study of Quality Certification System of Lithuania. Engineering Economics, n. 2, 2008. 78-84.

SEVERINO, A. J. Metodologia do Trabalho Cientifico. 23ª ed. São Paulo: Cortez, 2007.

SILVA FILHO, W. J. Transparência, reflexão e vicissitude. Kriterion, 52, n. 123, 2011. 213 236.

SZPER, R.; PRAKASH, A. Watchdogs and the Limits of Information-Based Regulation. Voluntas, 22, n. 1, 2011. 112-141.

REAd | Porto Alegre - Edição 77 - N 1 - janeiro/abril 2014 - p. 31-63 
Alexandre de Oliveira e Aguiar \& Pedro Luiz Côrtes

TINOCO, J. E. P.; ROBLES, L. T. A contabilidade da gestão ambiental e sua dimensão para a transparência empresarial: estudo de caso de quatro empresas brasileiras com atuação global.

Revista de Administração Pública, 40, n. 6, 2006. 1077-1096.

WERTHEIN, J. A sociedade da informação e seus desafios. Ciência da Informação, 29, n. 2, 2000. 71-77.

WOODS, M. The Global Reporting Initiative. The CPA Journal, 73, n. 6, 2003. 60-65.

WOODSIDE, A. Case Study Research: Theory, Methods and Practice. Bingley: Emerald Group Publishing, 2010. 455 p.

YIN, H.; SCHMEIDLER, P. J. Why Do Standardized ISO 14001 Environmental Management Systems Lead to Heterogeneous Environmental Outcomes? Business Strategy and the Environment 18, 469-486 (2009) DOI: 10.1002/bse.629

ZHU, Q. et al. Green supply chain management in leading manufacturers: case studies in Japanese large companies. Management Research Review, 33, n. 4, 2010. 380-392.

\section{AGRADECIMENTOS}

Este trabalho contou com o suporte do Fundo de Apoio a Pesquisa FAP/UNINOVE.

Nossa gratidão especial também às pessoas que nos ajudaram a situar a questão e atualizar informações sobre a ISO/IEC 17021 antes da realização da pesquisa propriamente dita, particularmente Joyce Bleeker (ISO, gerente sênior de projetos), John Owen (IAF, secretário) e Nigel Croft (ISO, chairman do TC/176/SC2 e membro do comitê de política do ISO/CASCO). 